\title{
Quälendes Mitbringsel nach Sex in den Tropen
}

\author{
Offenbar lässt sich eine Tinea genitalis sexuell gut \\ übertragen - Schweizer Ärzte berichten über eine Häu- \\ fung der Dermatophytose bei Südostasien-Reisenden. \\ Eine Genitalrasur scheint die Infektion zu erleichtern.
}

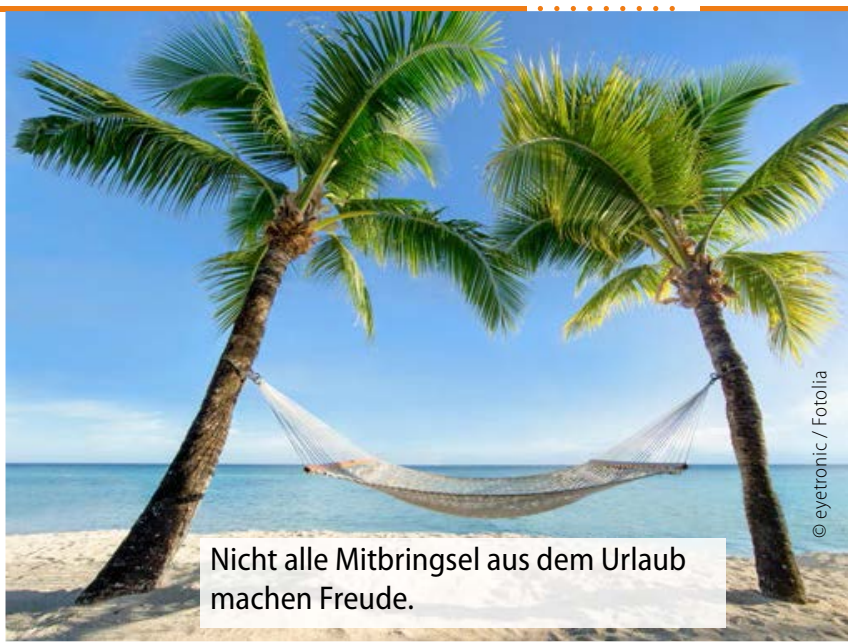

Auf dieses Urlaubsandenken hätte die 18-jährige Schwedin sicher gerne verzichtet: Als sie sich im Züricher Triemli-Hospital vorstellte, überzogen stark schmerzende gerötete und schuppende Plaques sowie follikuläre Pusteln ihre großen Schamlippen und den Venushügel. Die Blutuntersuchung ergab eine ausgeprägte Leukozytose und erhöhte Werte für C-reaktives Protein. Hautproben offenbarten unter dem Mikroskop eindeutig Pilzhyphen; in selektiven Agar-Kulturen ließ sich Trychophyton interdigitale als Übeltäter nachweisen.

Interessant an dem Fall ist nach Ansicht der Ärzte um Dr. Isabelle Luchsinger vor allem die Art und Weise, wie die junge Frau den Pilz erworben hat. Die Anamnese ergab, dass sie sich offenbar bei einem Touristen während eines Thailandurlaubs angesteckt hatte. Die Frau hatte nach eigenen Angaben mit dem Mann mehrfach geschützten $\mathrm{Ge}$ schlechtsverkehr.

\section{Fulminanter Verlauf mit ulzerierenden Knoten}

Die Schweizer Ärzte konnten die Patientin zwei Wochen nach Symptombeginn untersuchen und begannen sofort eine systemische Therapie mit Terbinafin $250 \mathrm{mg} / \mathrm{d}$ sowie eine Antibiose mit Amoxicillin/Clavulansäure, da sie eine bakterielle Superinfektion vermuteten. Die Antimykose schlug zunächst jedoch nicht an: Nach zwei Tagen kam es zu einer starken Entzündungsreaktion mit ulzerierenden Knoten und serös-eitrigem Ausfluss. Die Ärzte stellten nun auf Itraconazol $100 \mathrm{mg}$ dreimal täglich um und verabreichten zusätzlich Prednison. Aufgrund der starken Schmerzen wurde die Patientin zwei Wochen hospitalisiert. Nach drei Wochen Prednison und sechs Wochen Itraconazol heilten die Läsionen langsam ab, hinterließen jedoch markante Narben. Die junge Frau war jedoch kein
Einzelfall. Insgesamt sieben Patienten zwei Frauen und fünf Männer - kamen zwischen März und Juli 2014 mit ähnlichen Beschwerden ins Triemli-Hospital und die Züricher Uniklinik. Alle hatten in Südostasien Urlaub gemacht und sich dabei offenbar angesteckt - vier der Männer bei Prostituierten. Die Symptome waren bei allen ähnlich.

\section{Rasur ebnet Erregern den Weg}

Die Infektion kann, wie im beschriebenen Beispiel, sehr schwer und schmerzhaft verlaufen. Drei der Patienten benötigten eine zusätzliche Antibiose, fünf auch eine Behandlung mit Analgetika. Der Grund für den fulminanten Verlauf offenbarte sich in genetischen Analysen: Sämtliche nachgewiesenen Erreger gehörten zum Typ III und IV von T. interdigitale. Diese Stämme bevorzugen eigentlich Tiere, bei Menschen verursachen sie aber meist gravierende Infekte. Ein weiterer Grund für die ausgeprägten Läsionen offenbarte sich in der Anamnese: Die vier Patienten mit den schlimmsten Beschwerden hatten sich vor der Infektion regelmäßig den Genitalbereich rasiert. Da eine solche Rasur die epidermale Barriere schädigt, gehen die Dermatologen davon aus, dass dies den Eintritt der Erreger erleichtert hat. Als weiteren Faktor sehen sie die tropischen Temperaturen in Südostasien. Insgesamt seien sexuell übertragene Dermatophytosen in der Literatur bislang kaum beschrieben worden. Die Häufigkeit der Tinea genitalis bei Tropenurlaubern deute aber darauf, dass dieser Übertragungsweg bislang unterschätzt wurde, so die Dermatologen. (Thomas Müller)

Luchsinger, I. et al. Sex Transm Infect 2015;

doi:10.1136/sextrans-2015-052036

\section{Erkrankungsrisiko drastisch reduziert}

\section{Minocyclin bremst Multiple Sklerose}

\section{Das Antibiotikum Minocyclin verzö- gert bei Patienten mit einem ersten Krankheitsschub den Übergang in eine klinisch gesicherte MS. In einer Phase-III-Studie wurde die Konver- sionsrate im Vergleich zu Placebo fast halbiert.}

Offenbar lassen sich mit dem günstigen und seit langem generisch erhältlichen Antibiotikum Minocyclin bei Patienten nach einem ersten demyelinisierenden Ereignis (klinisch isoliertes Syndrom, CIS) erneute Schübe verhindern. Dies wird aus
Daten einer Phase-III-Studie deutlich, die beim europäischen MS-Kongress ECTRIMS in Barcelona vorgestellt worden ist. In der präsentierten Studie waren 143 Patienten entweder mit Minocyclin oder Placebo behandelt worden. Das überraschende Ergebnis: In den ersten sechs Monaten nach Studienbeginn konvertierten $61 \%$ unter Placebo, aber nur 34\% unter Minocyclin zu einer klinisch manifesten MS. Das Erkrankungsrisiko wurde damit knapp um die Hälfte (45\%) reduziert. (mut)

31. Kongress des ECTRIMS, Barcelona 2015 